\title{
Locus Of Control And Dysfunctional Audit Behavior
}

David O Bryan (Email: obryan@pittstate.edu) Pittsburg State University Jeffrey J. Quirin (Email: jeffrey.quirin@wichita.edu) Wichita State University David P. Donnelly (Email: donnellyd@umkc.edu) University of Missouri-Kansas City

\begin{abstract}
The Panel on Audit Effectiveness suggested that dysfunctional audit behavior (DAB) was associated with decreased audit quality (Public Oversight Board 2000). Recent, notable audit failures have also rekindled criticisms of audit quality. The current study presents the results of a survey in which 134 auditors were asked to report their perceived levels of three widely-cited DABs in their firms: occurrence of premature sign-offs, altering/replacing audit procedures, and underreporting of time. Although the overall results can be characterized as positive for the auditing profession, a systematic pattern in the results was identified. Specifically, statistical analysis suggests that perceptions of DAB were associated with a common personality variable, locus of control. Practical implications of this interesting finding are subsequently presented in the paper.
\end{abstract}

\section{LOCUS OF CONTROL AND DYSFUNCTIONAL AUDIT BEHAVIOR}

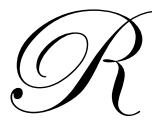
ecent, notable audit failures have rekindled criticisms of audit quality. The causes of audit failures can be numerous, but we know that some identifiable behaviors reduce audit quality. A relatively unexplored area of inquiry concerns whether or not these behaviors are systematically related to auditors' personality characteristics. That is, are some auditors inherently more likely to engage in behavior that would reduce audit quality?

\section{Dysfunctional Audit Behavior (DAB)}

Dysfunctional audit behavior (DAB) is the term used in the academic literature to describe behavior that contributes to reduced audit quality and, ultimately, audit failures. Two behaviors that directly affect audit quality include premature signing-off of audit steps without completion of the procedure (Otley and Pierce 1995; Rhode 1978; Alderman and Deitrick 1978) and the altering/replacing of audit steps (Margheim and Pany 1986).

Underreporting of audit time is an additional DAB, but one that has an indirect effect on audit quality (Smith 1995; Kelley and Margheim 1990; Lightner et al. 1982). The direct effect of underreporting time is primarily a management control issue and, although undesirable, does not directly effect audit quality. However, the negative side effects of underreporting time, such as unrealistic budgets and understaffing, may create time pressure that causes auditors to engage in direct forms of DAB, such as premature signing-off or altering/replacing audit steps.

\section{Purpose}

We surveyed auditors and asked them to report their perceived level of occurrence of premature sign-offs, altering/replacing audit procedures, and underreporting of time in their firms. In addition to the perceived level of occurrence, we also asked auditors about their acceptance of these behaviors. Finally, we asked the auditors in our sample to assess the likelihood that these behaviors would be detected by the control systems in their firms.

In a previous article (Donnelly et al., 2002) we reported the overall results, which we characterized as positive for the auditing profession. Perceived occurrence and acceptance of DAB were relatively low, and the perceived likelihood of detection of DAB was relatively higher. 
The purpose of this article is to report a systematic pattern in our results. We find that perceptions of DAB were associated with auditors $=$ locus of control. In the next section we briefly explain this personality variable and why it might be associated with DAB. This is followed by a discussion of our sample, results, and the practical implications of our findings.

\section{Locus of Control}

Rotter (1966) suggests that individuals develop generalized expectations concerning whether or not success in a given situation will be contingent on their own personal behavior, or be controlled by external forces. Individuals that tend to associate outcomes with their own efforts or believe that events are under their own control are referred to as internals, while externals are those who believe that they cannot control events or outcomes (Spector 1982). Thus, internally and externally directed people can encounter identical situations, yet perceive that their actions will have quite different impacts on their lives.

Locus of control is also highly correlated with Machiavellianism (Gable and Dangello 1994; Comer 1985; Solar and Bruehl 1971). Machiavellians are persons willing to sacrifice ethics to attain their objectives (Gable and Dangello 1994). In situations where they are unable to obtain the reinforcements needed for survival, they view manipulation of others as a necessary defense (Solar and Bruehl 1971). Machiavellian behavior is most likely to manifest itself in situations where there is a perception of a high degree of control (Gable and Dangello 1994).

Mudrack (1989) found that those persons whose locus of control was external tended to be Machiavellian. He concluded that the use of manipulation, deception, or ingratiation tactics may reflect an attempt on the part of the external to assert some influence over an environment that lends itself more suitable to internally-oriented approaches. In an auditing context, Machiavellians might be more likely to resort to DAB to cope with the pressures of the audit environment.

These behaviors allow the external-Machiavellian a way to manipulate the audit process to achieve desirable performance objectives. The reduction in audit quality resulting from these actions is viewed as a necessary sacrifice in order for the individual to survive in the audit environment. In addition, the outcome of the audit process is not perceived by the external-Machiavellian to be greatly influenced by their actions. That is, premature sign-off or altering/reducing audit procedures are not perceived to be audit quality reducing acts. In a sense, the outcome of the audit process is Adestinye and largely perceived to be unaffected by the actions of the external.

\section{Sample}

Surveys were distributed to a total of 205 auditors from a cross-section of 10 public accounting firms. These firms were diverse and included Big 5, large international, large national, multi-state regional, and single state. An office partner gave a survey to each potential respondent. Accompanying each questionnaire was a cover letter explaining the research as well as instructions for completing the survey. A self-addressed, stamped envelope was included for respondents to return their survey directly to us.

Of the 205 surveys distributed, respondents returned a total of 134 usable surveys for an effective response rate of 65 percent. The average respondent was 29 years old and had 6 years of audit experience. Females represented approximately 48 percent of the returned instruments.

Locus of control was measured using the 16-item, Spector (1988) work locus of control scale. The Spector (1988) measure has been shown to be significantly related to such work related outcomes as job satisfaction, organizational commitment, role stress, and leadership behavior. Following prior literature, those respondents above the median on the Spector scale were classified as externals and those below the median were classified as internals. This resulted in an equal number of internals and externals (67) in our sample. 


\section{Results}

The survey included three sections corresponding to the perceived occurrence of DAB, the acceptance of these behaviors, and the likelihood of detection. Responses were elicited on a seven-point Likert-type scale with 1 being Astrongly disagree@ and 7 being Astrongly agree@ with the corresponding question. The mean responses and practical implications for each of these three sections are presented the following subsections.

Occurrence of DAB. The mean perceived level of occurrence of the three DABs is reported in Table 1. Altering/replacing audit procedures was perceived to have the highest level of occurrence followed by underreporting time. Premature sign-off was perceived to have the lowest level of occurrence. This rank ordering was the same for both internals and externals.

Table 1 Occurrence of Dysfunctional Audit Behaviors

\begin{tabular}{|c|c|c|}
\hline Question & $\begin{array}{l}\text { Externals } \\
\text { Mean Response } \\
\text { (Std. Dev.) }\end{array}$ & $\begin{array}{l}\text { Internals } \\
\text { Mean } \\
\text { Response } \\
\text { (Std. Dev.) }\end{array}$ \\
\hline $\begin{array}{l}\text { Some auditors in my firm sign-off required audit steps, not covered by other audit } \\
\text { steps, without completing the work or noting the omissions of procedures (hereafter } \\
\text { referred to as Apremature sign-offe.) }\end{array}$ & $\begin{array}{l}3.48 * * \\
(1.62)\end{array}$ & $\begin{array}{l}2.42 * * \\
(1.29)\end{array}$ \\
\hline Auditors in my firm underreport the time it takes to complete an audit step. & $\begin{array}{l}3.82 * * \\
(1.81)\end{array}$ & $\begin{array}{l}2.78 * * \\
(1.65)\end{array}$ \\
\hline $\begin{array}{l}\text { Auditors in my firm will alter or replace time-consuming audit procedures with less } \\
\text { time-consuming procedures. Example-relying on inquiry of client rather than using } \\
\text { stronger forms of evidence that are more appropriate and time-consuming. }\end{array}$ & $\begin{array}{l}3.96 * \\
(1.48)\end{array}$ & $\begin{array}{l}3.46^{*} \\
(1.49)\end{array}$ \\
\hline
\end{tabular}

** Indicates difference between external and internal means is significant at .01 level.

* Indicates difference between external and internal means is significant at .05 level.

Note that externals perceived all three behaviors to have a higher level of occurrence than did internals. This difference was statistically significant at the $\mathrm{p}<.05$ level for altering/replacing audit procedures and at the $\mathrm{p}<.01$ level for underreporting time and premature sign-off.

Self-reported levels of occurrence can be correlated with respondents= actual behavior and/or behavioral intentions. That is, when asked whether Asome auditors in my firm@ engage in this behavior respondents often project their own behavior into the response. To the extent this is happening in our sample, this strongly suggests that externals are more likely to engage in these three, dysfunctional behaviors.

Acceptance of DAB. In addition to the level of occurrence of DAB, we were also interested in the acceptance of these behaviors. Table 2 reports the mean response on three, multiple-part questions. An examination of the total scores for each of the three questions (superscripted a, b, and c) reveals that both internals and externals reported the highest level of acceptance for altering/replacing audit procedures and the lowest level of acceptance for underreporting time. 
Table 2 Acceptance of Dysfunctional Audit Behaviors

\begin{tabular}{|c|c|c|}
\hline Question & $\begin{array}{l}\text { Externals } \\
\text { Mean } \\
\text { Response (Std. } \\
\text { Dev.) }\end{array}$ & $\begin{array}{l}\text { Internals } \\
\text { Mean } \\
\text { Response } \\
\text { (Std. Dev.) }\end{array}$ \\
\hline I am more accepting of auditors engaging in premature sign-off if: & $\begin{array}{l}11.58^{\mathrm{a} * *} \\
(5.56)\end{array}$ & $\begin{array}{l}9.19^{\mathrm{a} * *} \\
(5.08)\end{array}$ \\
\hline They believe the audit step will not find anything wrong if completed. & $\begin{array}{l}2.91 * * \\
(1.65)\end{array}$ & $\begin{array}{l}2.07 * * \\
(1.47)\end{array}$ \\
\hline $\begin{array}{l}\text { On previous audits there were no problems with this part of the client }=\mathrm{s} \\
\text { system/records. }\end{array}$ & $\begin{array}{l}2.99 * * \\
(1.77)\end{array}$ & $\begin{array}{l}2.15^{* *} \\
(1.41)\end{array}$ \\
\hline $\begin{array}{l}\text { The audit supervisor shows strong concern over the time it's taking to complete the } \\
\text { audit step and is putting pressure on getting it done. }\end{array}$ & $\begin{array}{l}2.22 \\
(1.44)\end{array}$ & $\begin{array}{l}1.88 \\
(1.26)\end{array}$ \\
\hline They believe the audit step is unnecessary. & $\begin{array}{l}3.46 \\
(1.88)\end{array}$ & $\begin{array}{l}3.09 \\
(1.94)\end{array}$ \\
\hline I am more accepting of auditors underreporting their time if: & $\begin{array}{l}8.97^{\mathrm{b} * *} \\
(5.24)\end{array}$ & $\begin{array}{l}6.91^{\mathrm{b} * *} \\
(4.12)\end{array}$ \\
\hline It improves their chances for promotion and advancement. & $\begin{array}{l}2.18 * \\
(1.39)\end{array}$ & $\begin{array}{l}1.72 * \\
(1.11)\end{array}$ \\
\hline It improves their performance evaluation. & $\begin{array}{l}2.19^{*} \\
(1.37)\end{array}$ & $\begin{array}{l}1.76^{*} \\
(1.19)\end{array}$ \\
\hline It is suggested by their immediate supervisor. & $\begin{array}{l}2.25^{*} \\
(1.51)\end{array}$ & $\begin{array}{l}1.72 * \\
(1.17)\end{array}$ \\
\hline Others underreport their time and it's necessary to compete with them. & $\begin{array}{l}2.34 * * \\
(1.63)\end{array}$ & $\begin{array}{l}1.72 * * \\
(1.08)\end{array}$ \\
\hline I am more accepting of auditors altering/replacing audit procedures if: & $\begin{array}{l}15.07^{\mathrm{C} * *} \\
(5.19)\end{array}$ & $\begin{array}{l}12.63^{\mathrm{c} * *} \\
(5.06)\end{array}$ \\
\hline They believe the original audit procedure was unnecessary. & $\begin{array}{l}4.75 \\
(1.54)\end{array}$ & $\begin{array}{l}4.54 \\
(1.79)\end{array}$ \\
\hline On previous audits there were no problems with this part of the client's system. & $\begin{array}{l}4.16^{* *} \\
(1.57)\end{array}$ & $\begin{array}{l}3.45^{* *} \\
(1.67)\end{array}$ \\
\hline They do not believe the original procedure would find anything wrong. & $\begin{array}{l}3.40 * * \\
(1.74)\end{array}$ & $\begin{array}{l}2.70 * * \\
(1.52)\end{array}$ \\
\hline They are under a lot of time pressure to complete the audit. & $\begin{array}{l}2.76^{* *} \\
(1.62)\end{array}$ & $\begin{array}{l}1.94 * * \\
(1.28)\end{array}$ \\
\hline \multicolumn{3}{|l|}{ Represents total acceptance level of premature sign-off } \\
\hline \multicolumn{3}{|l|}{ Represents total acceptance level of underreporting of time. } \\
\hline \multicolumn{3}{|l|}{ Represents total acceptance level of altering/replacing audit procedures. } \\
\hline $\begin{array}{l}\text { * Indicates difference between external and internal means is significant at } .01 \text { level. } \\
\text { Indicates difference between external and internal means is significant at } .05 \text { level. }\end{array}$ & & \\
\hline
\end{tabular}

It is somewhat disturbing that the two behaviors that directly influence audit quality (i.e., premature sign-off and altering/replacing audit procedures) have a higher level of acceptance than underreporting time. This may be due to the fact that for most respondents underreporting of time has the greatest effect on their work routine. That is, below the partner level auditors may fail to appreciate the grave consequences of audit failures, but they are acutely aware of the pressures that can result from an inaccurate time budget.

The striking result in Table 2 is that externals report a higher level of acceptance for the three dysfunctional behaviors than do internals. This is true for the total scores on the three, multiple part questions and for every subpart of each question. These differences are statistically significant at the $\mathrm{p}<.01$ level for the total scores (superscripted a, $\mathrm{b}$, and $\mathrm{c}$ ). Of the 12 subparts, six are significantly different at the $\mathrm{p}<.01$ level and three at the $\mathrm{p}<.05$ level. Only three of the 12 subparts were not significantly different between internals and externals. 
This pattern is fairly compelling and suggests that externals have a higher level of acceptance for these behaviors. These results do not explain why externals have a higher level of acceptance of DAB, but they do provide a potential means to identify the auditors most accepting of these DABs.

Likelihood of Detection. The auditors in our sample were also asked to report their perception of the likelihood that these three behaviors would be detected by their firms. Table 3 reports these responses. Altering/replacing audit procedures was perceived to have the highest likelihood of detection followed by premature sign-off. Underreporting time was the behavior auditors perceived to be least likely to be detected. This is an encouraging result. Of the three behaviors, underreporting time may be the Alesser of the three evils@ since it does not directly reduce audit quality.

Table 3 Likelihood of Detection of Dysfunctional Audit Behaviors

\begin{tabular}{|c|c|c|}
\hline Question & $\begin{array}{l}\text { Externals } \\
\text { Mean } \\
\text { Response } \\
\text { (Std. Dev.) } \\
\end{array}$ & $\begin{array}{l}\text { Internals } \\
\text { Mean } \\
\text { Response } \\
\text { (Std. Dev.) } \\
\end{array}$ \\
\hline $\begin{array}{l}\text { Supervisors in my firm, through workpaper review or other evaluation procedures, } \\
\text { would most likely detect: }\end{array}$ & $\begin{array}{l}11.88^{\mathrm{a} *} \\
(3.43)\end{array}$ & $\begin{array}{l}13.19^{\mathrm{a}} * \\
(3.02)\end{array}$ \\
\hline If auditors underreport their time. & $\begin{array}{l}2.84 \\
(1.50)\end{array}$ & $\begin{array}{l}3.03 \\
(1.40) \\
\end{array}$ \\
\hline If auditors were to prematurely sign-off on an audit step. & $\begin{array}{l}4.12 * \\
(1.56) \\
\end{array}$ & $\begin{array}{l}4.66^{*} \\
(1.48) \\
\end{array}$ \\
\hline If auditors were to alter/replace assigned audit procedures. & $\begin{array}{l}4.93 * * \\
(1.32)\end{array}$ & $\begin{array}{l}5.48 * * \\
(1.17)\end{array}$ \\
\hline
\end{tabular}

Comparing the responses of internals and externals in Table 3 yields another pattern between the two groups. Externals perceived the likelihood of detection to be lower for each of the three behaviors. For the total score, this difference is significant at the $p<.05$ level. Altering/replacing audit procedures was significant at the $p<.01$ level while premature sign-off was significant at the $\mathrm{p}<.05$ level. Underreporting time was the only subpart that was not significantly different between internals and externals.

The Likelihood of detection and the resulting sanctions likely serve as a deterrent for many auditors. As a group, externals perceive the likelihood of detection is lower and, therefore, may be more likely to engage in the behaviors discussed.

\section{SUMMARY AND IMPLICATIONS}

The results reported in this paper suggest that the personality construct, locus of control, may be useful in managing DAB within audit firms. In this sample, auditors classified as externals perceived that DAB occurred at higher levels and they were more accepting of this behavior than were internals. Perhaps most disturbing was the finding that externals also perceived a lower level of likelihood of detection than did internals. In comparison to internals, the responses of externals could be characterized as, ADAB occurs, I accept it, and I don=t think it will be detected.e 
From a risk management perspective within audit firms, these results have practical implications. Efforts to educate auditors about the consequences of reduced audit quality, and ongoing efforts to monitor DAB, will be most efficient and effective if concentrated on externals. Our results suggest that this group is at a much higher risk of engaging in $\mathrm{DAB}$ than are internals.

Additional research is warranted to determine whether the results reported in this paper are generalizable. In addition, these results only suggest that externals are more likely to engage in DAB. Future research is needed to determine whether these perceptions on the part of externals actually lead to a higher incidence of such behavior in actual audit settings.

\section{REFERENCES}

1. Alderman, C. W. and J. W. Deitrick. 1978. Survey of the Impact of Time Budgets on Audit Performance. Proceedings, American Accounting Association, Southeastern Regional Meeting, Sarasota, Florida: 456-474.

2. Comer, J. M. 1985. Machiavellianism and Inner vs Outer Directedness: A Study of Sales Managers. Psychological Reports 56: 81-82.

3. Donnelly, D., J. Quirin and D. O’Bryan, 2002, The Perceived Occurrence and Acceptance of Dysfunctional Audit Behavior, Journal of Forensic Accounting, III(2), December: 245-52.

4. Gable, M. and F. Dangello. 1994. Locus of Control, Machiavellianism, and Managerial Job Performance. The Journal of Psychology 128: 599-608.

5. Kelley, T. and L. Margheim. 1990. The Impact of Time Budget Pressure, Personality, and Leadership Variables on Dysfunctional Auditor Behavior. Auditing: A Journal of Practice \& Theory 9: 21-42.

6. Lightner, S. M., S. J. Adams, and K. M. Lightner. 1982. The Influence of Situational, Ethical, and Expectancy Theory Variables on Accountants= Underreporting Behavior. Auditing: A Journal of Practice \& Theory 2: 1-12.

7. Margheim, L. and K. Pany. 1986. Quality Control, Premature Signoff, and Underreporting of Time: Some Empirical Findings. Auditing: A Journal of Practice \& Theory 7: 50-63.

8. Mudrack, P. E. 1989. Machiavellianism and Locus of Control: A Meta-analytic Review. The Journal of Social Psychology 130: 125-126.

9. Otley, D. and B. Pierce. 1995. The control problem in public accounting firms: An empirical study of the impact of leadership style. Accounting, Organizations and Society 20: 405-420.

10. Rhode, J. G. 1978. Survey on the Influence of Selected Aspects of the Auditor=s Work Environment on Professional Performance of Certified Public Accountants. Issued as the Independent Auditor $=\mathrm{s}$ Work Environment: A Survey. New York, NY: American Institute of Certified Public Accountants.

11. Rotter, J. B. 1966. Generalized Expectancies for Internal Versus External Control of Reinforcement. Psychological Monographs 80 (1): Whole No. 609.

12. Smith, R. 1995. Underreporting Time: An Analysis of Current Tax Practice. Journal of Applied Business Research 11: 39-45.

13. Solar, D. and D. Bruehl. 1971. Machiavellianism and Locus of Control: Two Conceptions of Interpersonal Power. Psychological Reports 29: 1079-1082.

14. Spector, P. E. 1982. Behavior in Organizations as a Function of Employee $=\mathrm{s}$ Locus of Control. Psychological Bulletin 91: 482-497.

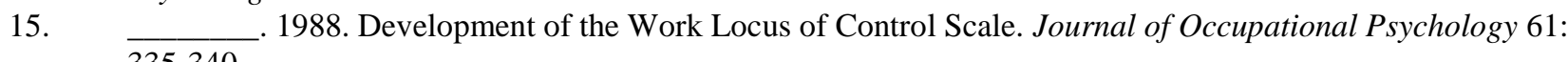
$335-340$. 